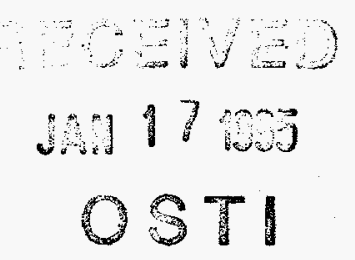

\title{
A Two-Stage Pneumatic Repeating Pellet Injector for Refueling Magnetically Confined Plasmas in Long-Pulse Fusion Experiments
}

\author{
S. K. Combs, S. L. Milora, and C. R. Foust

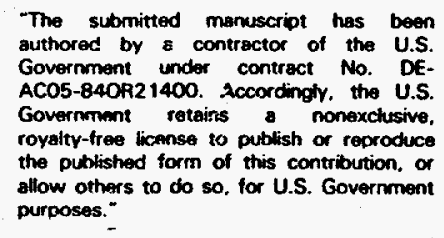

A. Frattolillo, S. Migliori, F. Scaramuzzi, M. Capobianchi, C. Domma, and G. Ronci

ENEA, Centro Ricerche Energia Frascati, Frascati, Rome, Italy

Oak Ridge National Laboratory, Oak Ridge, Tennessee, 37831-8071, USA

DISCLAIMER

\begin{abstract}
This report was prepared as an account of work sponsored by an agency of the United States Government. Neither the United States Government nor any agency thereof, nor any of their employees, makes any warranty, express or implied, or assumes any legal liability or responsibility for the accuracy, completeness, or usefulness of any information, apparatus, product, or process disclosed, or represents that its use would not infringe privately owned rights. Reference herein to any specific commercial product, process, or service by trade name, trademark, manufacturer, or otherwise does not necessarily constitute or imply its endorsement, recommendation, or favoring by the United States Government or any agency thereof. The views and opinions of authors expressed herein do not necessarily state or reflect those of the United States Government or any agency thereof.
\end{abstract}




\title{
A Two-Stage Pneumatic Repeating Pellet Injector for Refueling Magnetically Confined Plasmas in Long-Pulse Fusion Experiments
}

\author{
A. Frattolillo, S. Migliori, F. Scaramuzzi, M. Capobianchi, C. Domma, and G. Ronci \\ ENEA, Centro Ricerche Energia Frascati, Frascati, Rome, Italy \\ S. K. Combs, ${ }^{*}$ S. L. Milora, ${ }^{*}$ and C. R. Foust* \\ Oak Ridge National Laboratory, Oak Ridge, Tennessee, 37831-8071, USA
}

\begin{abstract}
An experiment to demonstrate the feasibility of a repetitive pneumatic pellet injector at $1 \mathrm{~Hz}$ in the velocity range of 2 to $3 \mathrm{~km} / \mathrm{s}$ was carried out in a collaboration between Oak Ridge National Laboratory and ENEA Frascati, in the context of a cooperative agreement between the U.S. Department of Energy and EURATOM-ENEA Association. The third round of this experiment was completed in May 1995. Both the operation and performance of the equipment were improved, and the original objectives of the collaboration have been met.

The facility was also briefly operated with neon pellets to explore the potential for producing fast "killer" pellets for disruption amelioration applications. Speeds of $1.7 \mathrm{~km} / \mathrm{s}$ were achieved using a piston mass of $43 \mathrm{~g}$. Higher speeds should be achievable with a system specifically designed for neon or other higher $Z$ gases. Finally, tests were performed with thin boron carbide coatings $(2 \mu \mathrm{m})$ on the Ergal pistons. The test results were encouraging because piston friction was reduced as was the piston wear.
\end{abstract}

\section{INTRODUCTION}

The projected fueling requirements of future magnetic confinement fusion devices, for example, the International Thermonuclear Experimental Reactor (ITER), indicate the need for a flexible plasma fueling capability, including both gas puffing and low- and high-speed pellet injection [1]. Conventional injectors, based on single-stage pneumatic guns or centrifuges, can reliably provide frozen pellets (1- to 6-mm-diam sizes) at speeds up to $1.3 \mathrm{~km} / \mathrm{s}$ and at suitable repetition rates ( 1 to $10 \mathrm{~Hz}$ or greater). Injectors based on twostage pneumatic guns and in situ condensation of hydrogen pellets can reliably achieve velocities over $3 \mathrm{~km} / \mathrm{s}$ [2,3]; however, they are not suitable for long-pulse repetitive operations. In this frame, an experiment in collaboration between Oak Ridge National Laboratory (ORNL) and ENEA Frascati was carried out to demonstrate the feasibility of a high-speed (2- to $3-\mathrm{km} / \mathrm{s})$ repeating $(-1-\mathrm{Hz})$ pneumatic pellet injector for longpulse operation. A test facility, described in detail in [4-6], was assembled at ORNL (Fig. 1); it combined a Frascati repeating two-stage light-gas gun and an existing ORNL deuterium extruder, equipped with a pellet chambering

\footnotetext{
* Research sponsored by the Office of Fusion Energy, U.S. Department of Energy, under contract DE-AC05-84OR21400 with Lockheed Martin Energy Systems, Inc.
}

mechanism/gun barrel assembly. It was operated in the course of three joint experimental campaigns in September-October 1993 (4 weeks) [5], June 1994 (3 weeks) [6], and May 1995 ( 3 weeks). In this paper we briefly describe the results of this third experimental campaign.

In tokamak fusion reactors, plasma disruptions can considerably damage the material surfaces of the first wall and divertor components due to the intense heat flux generated by the rapid and local deposition of the plasma energy. A proposed method for reducing the undesired effects of plasma disruptions is the injection of high-speed pellets to introduce impurities in the plasma and produce strong radiation, which dumps the plasma energy quickly but uniformly on the first wall [7]. From this perspective, the test facility was operated on the final day of the campaign with neon pellets to explore the potential for producing such fast "killer" pellets. We also briefly report on the encouraging results achieved in these preliminary tests.

\section{OPERATIONS}

The equipment was prepared for operation on the first day of the campaign, and it was operated for 14 consecutive working days thereafter. Data were generated in single-shot and repetitive $(1-\mathrm{Hz})$ modes in various gun configurations (pump tube lengths of 35,45 , and $100 \mathrm{~cm}$ and piston masses of 10 , 13.6 , and $43 \mathrm{~g}$ ) for deuterium pellets of nominal $2.7-\mathrm{mm}$ diameter. On the final day of the campaign, the equipment was operated with neon pellets to explore the potential for producing fast "killer" pellets for disruption amelioration. In all, nearly 2,000 shots were logged on the system, and for the most part, the data acquisition system was fully operational.

No operational difficulties of any sort were attributable to the cryostat or extruder, and at no time did we experience impact of the piston on the pump tube head. This point is extremely important because it concerns the reliability of the system from the perspective of eventual operation on a tokamak device. We attribute the improvement in this reliability to the addition of a check valve at the breech of the gun. This valve opens at a prescribed pressure and effectively eliminates premature movement of the pellet and escape of propellant gas resulting from the low inherent attaching force of extruded pellets to the gun barrel walls [6]. We think this innovation will greatly improve the consistency of performance and reliability of repeating two-stage gas gun systems. 


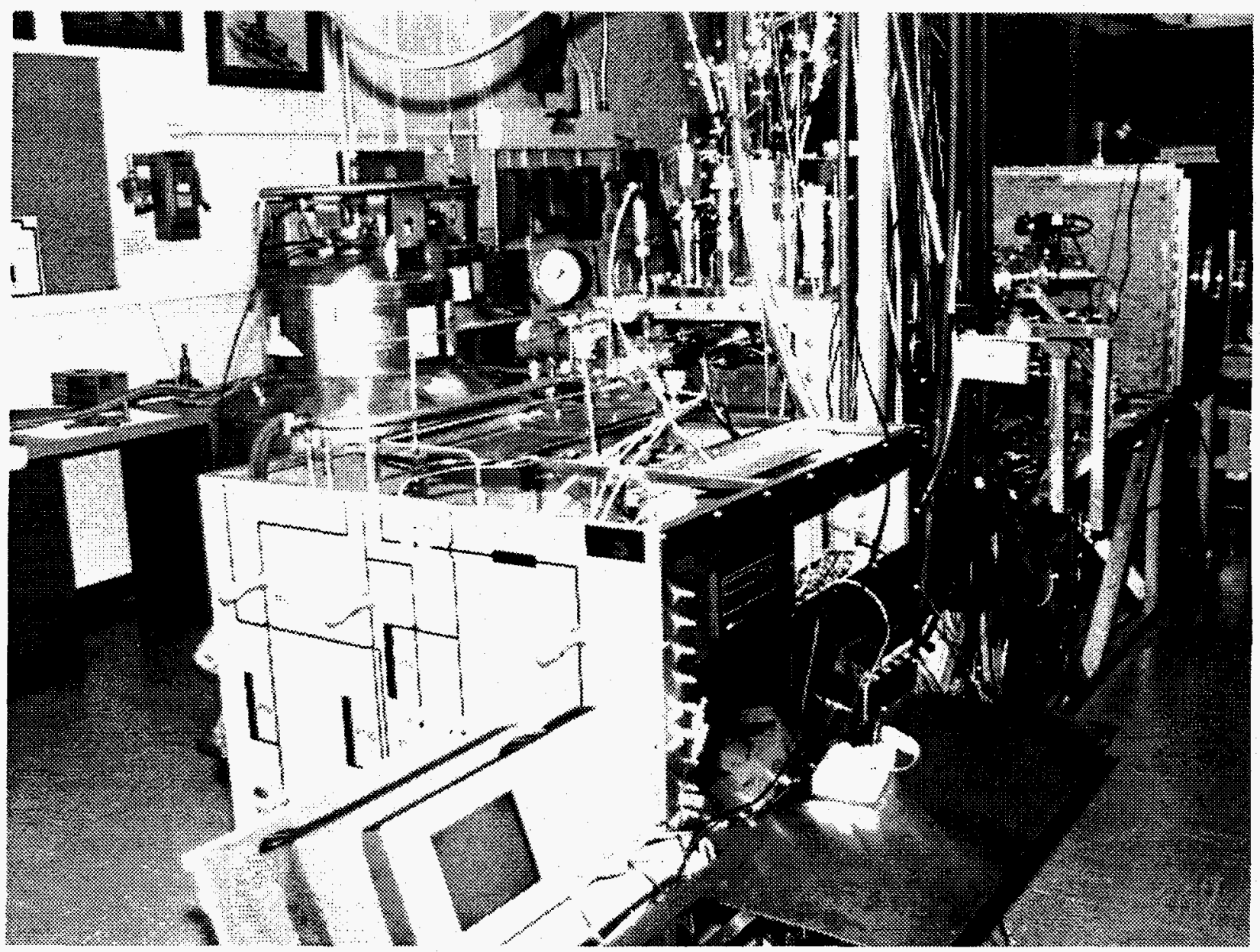

Fig. 1 The test facility at ORNL.

Finally we conducted a few tests with thin boron carbide coatings $(2 \mu \mathrm{m})$ on the Ergal pistons. Piston friction was reduced as was the piston wear, at least over the limited time span in which the tests were performed. Longer lifetime tests with thicker coatings will be performed separately at Frascati.

\section{PERFORMANCE}

The performance of the system is summarized in the following section, with reference to Figs. $2-4$. We have plotted the muzzle velocity as a function of breech pressure measured downstream of the check valve.

\section{A. Deuterium pellets; single-shot mode operation}

In the 1994 campaign we first demonstrated the feasibility of the check valve concept and obtained a limited amount of data in this configuration. The highest velocity recorded was slightly in excess of $2.5 \mathrm{~km} / \mathrm{s}$, and this was achievable only with 1-m-long pump tubes.

In the most recent campaign, the velocity scaling obtained in the 1994 campaign was verified (Fig. 2), but the results have been extended to a shorter pump tube length, namely $45 \mathrm{~cm}$. We think that the improved performance is due to an increase in the efficiency of the two-stage gun and to a better interface between the ORNL and Frascati systems (including the new check valve design).

\section{B. Deuterium pellets; repetitive mode operation}

As a point of reference, in 1994 the maximum achievable velocity in repetitive mode operation was limited to $1.6 \mathrm{~km} / \mathrm{s}$ at $0.5 \mathrm{~Hz}$ and $2.2 \mathrm{~km} / \mathrm{s}$ at $0.2 \mathrm{~Hz}$. These data were obtained for pump tube lengths of $1 \mathrm{~m}$. In contrast to these earlier results, $1-\mathrm{Hz}$ operation was achieved routinely in the recent campaign using the $45-\mathrm{cm}$ pump tube, and the performance under repeating conditions was found to be indistinguishable from single pellet results over the entire range of parameters explored (Fig. 3). From the data we conclude that the limit for acceleration of extruded pellets in the present gun configuration is $2.5 \mathrm{~km} / \mathrm{s}$, as determined by pellet fracturing. Note that we did not have time to modify the equipment in any way to explore whether this limit could be exceeded (longer barrel lengths or different check valve characteristics, for example).

\section{NEON PELLET ACCELERATION RESULTS}

In tests performed with a single-stage gas gun, the ORNL extruder was operated with neon gas feed, allowing the 


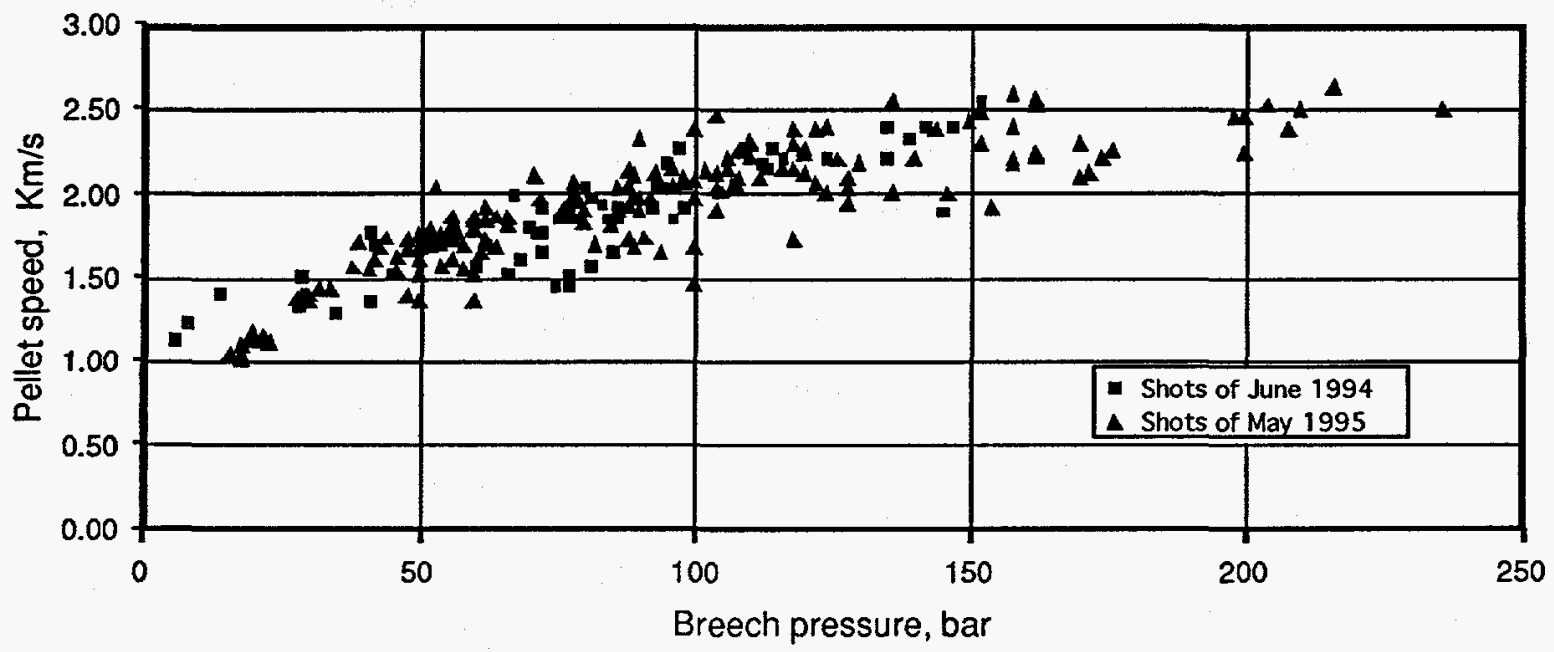

Fig. 2 Comparison of June 1994 and May 1995 results.

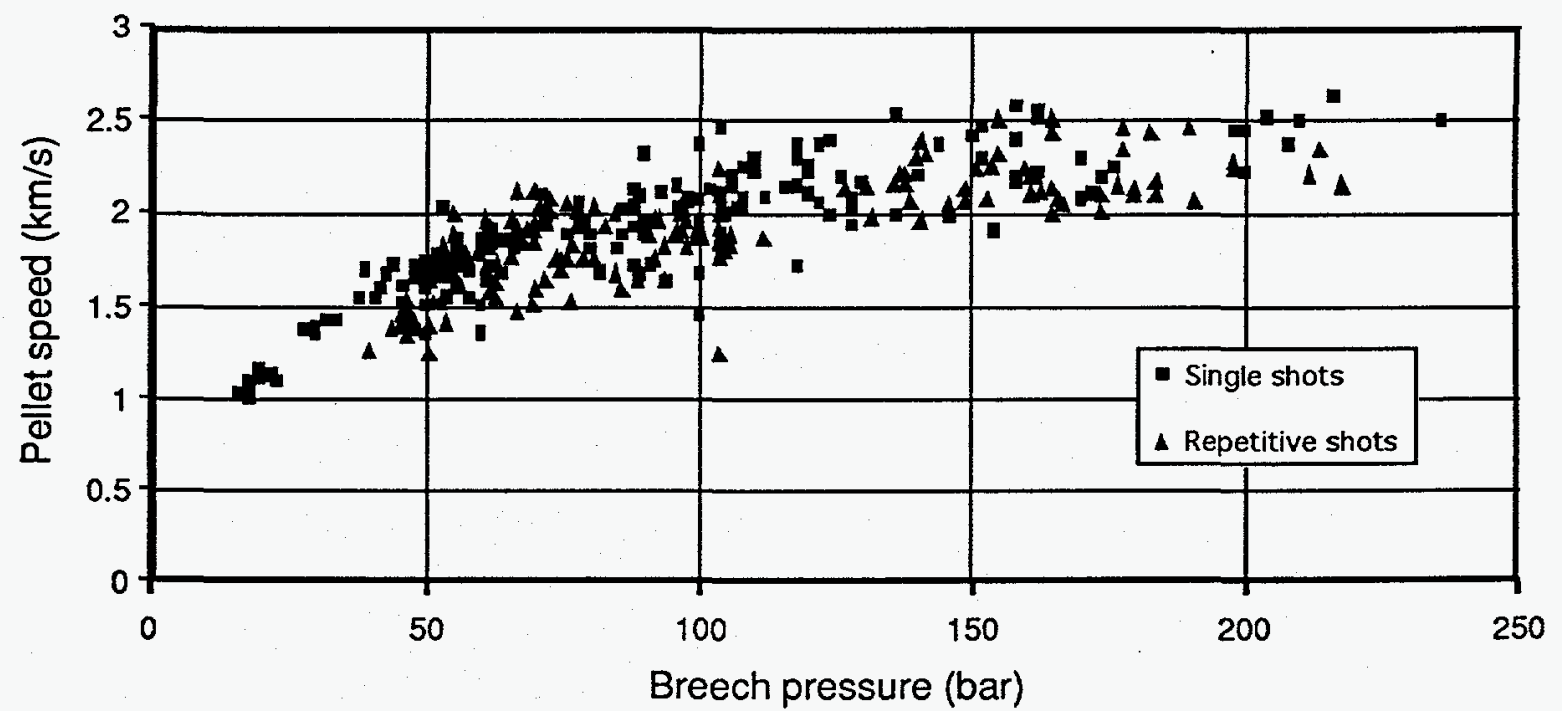

Fig. 3 Comparison of single-shot and repetitive mode operation.

acceleration of frozen neon pellets to about $600 \mathrm{~m} / \mathrm{s}$. During the last day of the latest campaign, tests were performed with the Frascati two-stage gun. In these limited tests we did not have the opportunity to optimize the gun geometry for the much heavier neon pellets. Nevertheless, speeds of $1.7 \mathrm{~km} / \mathrm{s}$ were easily achieved using a piston mass of $43 \mathrm{~g}$ (Fig. 4). Higher speeds should be achievable with a system specifically designed for neon or other higher $\mathrm{Z}$ gases. Should fast killer pellets be required on ITER for disruption amelioration, this technology would be applicable.

\section{FUTURE DIRECTIONS}

At this point the feasibility demonstration of the two-stage pneumatic repeating pellet injector has been given. In the near future it would be useful to prepare a preliminary design of an integrated long-pulse system aimed at a demonstration of this technology on a tokamak experiment. This would help in identifying the areas where additional development might be required and would address the feasibility of the concept under real world conditions.

Also, we have identified a few areas where improvements made in the short term would greatly facilitate improved reliability and perhaps lead to even better performance. This list would include an improved check valve design, better gas isolation valves, improved diagnostics, more wear-resistant pistons, and a new pellet chambering mechanism based on the design used on the Joint European Torus multipellet injector. 


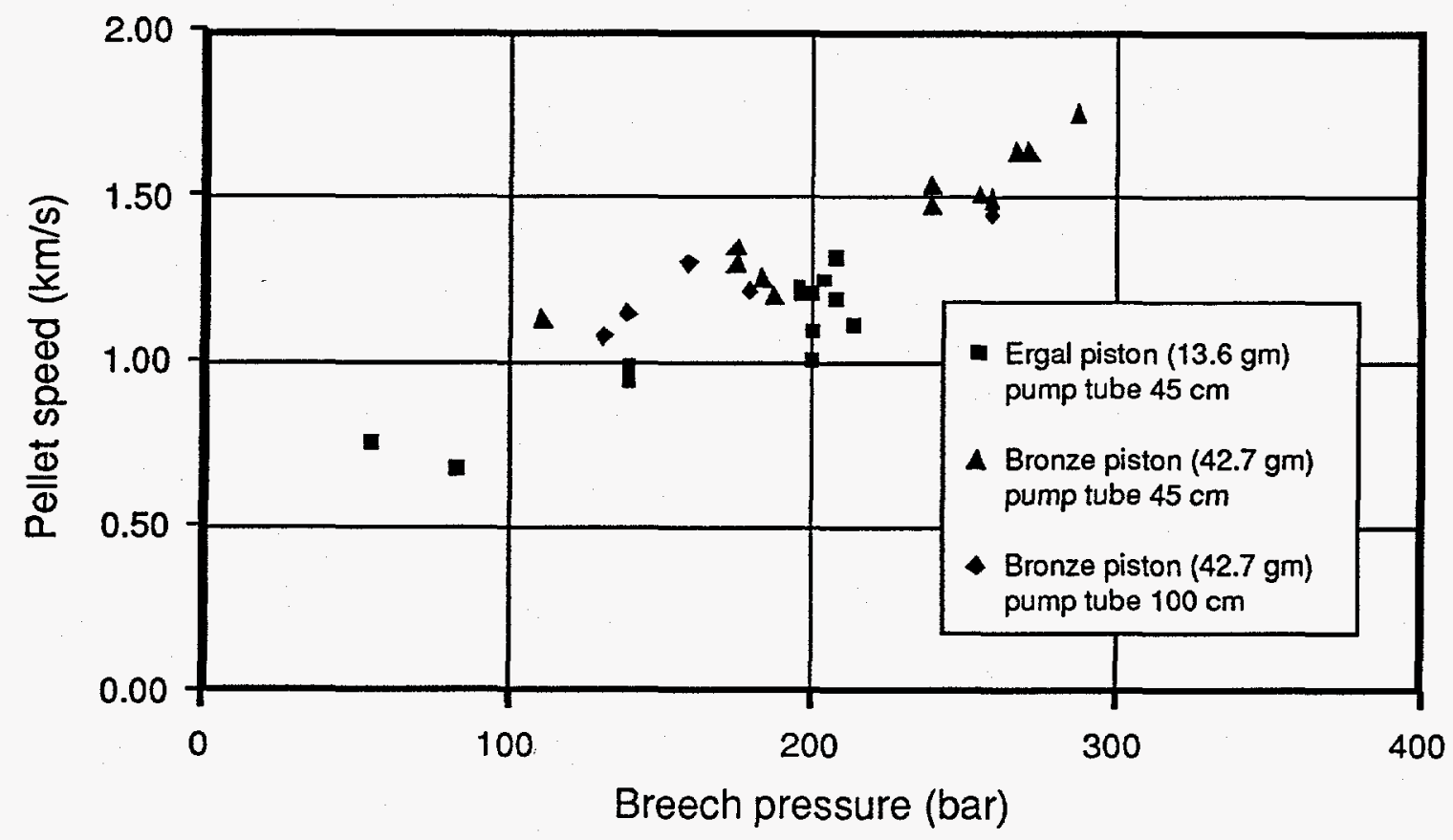

Fig. 4 Neon pellet acceleration results.

\section{REFERENCES}

[1] W. A. Houlberg, S. E. Attenberg, and M. J. Grapperhaus, "Density profile control in a fusion reactor using pellet injection," unpublished.

[2] A. Frattolillo et al., " $3.3 \mathrm{~km} / \mathrm{s}$ solid $D_{2}$ single pellet injector for the Frascati Tokamak Upgrade," Proceedings of the IEEE 14th Symposium on Fusion Engineering, San Diego, CA, U.S.A., Sept. 30-Oct. 3, 1991, IEEE, New York, 1991, p. 721.[3] J. P. Perin and A. Géraud., " $3400 \mathrm{~m} / \mathrm{s}$ deuterium pellet injector for Tore Supra," in Fusion Technology 1994, Proceedings of the 18th Symposium, Karlsruhe, Germany, 1994, North Holland, Amsterdam, 1995, Vol. 1, pp. 645-648.

[4] A. Frattolillo et al., "High-Speed Repetitive Pellet Injector Prototype for Magnetic Confinement Fusion Devices," in Fusion Technology 1992 (Proc. 17th Symposium, Rome, Italy, September 14-18, 1992) Vol. I, C. Ferro,
M. Gasparotto, and H. Knoepfel, Eds., North-Holland: Elsevier Science Publishers B. V., 1993, pp. 500-504.

[5] S. K. Combs et al., "High speed repetitive pellet injector for plasma fueling of magnetic confinement fusion devices," Proceedings of the IEEE 15th Symposium On Fusion Engineering, Hyannis (Boston), MA, U.S.A., 11-15 Oct. 1993.

[6] A. Frattolillo et al., "An high-speed repeating pellet injector for longpulse magnetic confinement fusion experiments," unpublished.

[7] R. Yoshino et al., "Disruption amelioration experiments in JT-60U and JET," in Proceedings of the 15th International Conference on Plasma Physics and Contralled Thermonuclear Research 1994, Seville, International Atomic Energy Commission, Vienna, 1995, IAEA-CN-60/A-5-II-2, unpublished. 